\title{
Grouting Model Experiment of Karst Aquifer under Dynamic Water Pressure and Confining Pressure
}

\author{
Zhou Shengquan ${ }^{1, *}$, Zhou Dawei ${ }^{1}$ and Sudipta Halder ${ }^{2}$ \\ ${ }^{1}$ School of Civil Engineering and Architecture, Anhui University of Science and Technology, Huainan 232001, China \\ ${ }^{2}$ Department of Mechanical Engineering, National Institute of Technology Silchar, Silchar 788010, India
}

Received 8 January 2018; Accepted 10 July 2018

\begin{abstract}
Grouting plays an important role in the construction of projects. The influence of dynamic water pressure and confining pressure on grouting has not been considered by traditional grouting theory. This study used a "geological engineering multifunctional experimental system" to explore the influence mechanism of dynamic water pressure and confining pressure on the grouting effect. Four groups of indoor grouting model experiments were adopted and compared. The influence of dynamic water pressure and confining pressure on the grouting effect was analyzed under different conditions. Experimental results demonstrate that the diffusion of the slurry is divided into pressure diffusion and migration diffusion. The dynamic water pressure causes the grouting slurry to be diluted, and the pressure in the cracks of the rock mass structure increases. As a result, serious loss of slurry occurs, and the slurry obviously shows migration diffusion. The confining pressure leads to closing of structural cracks, and the grouting effect of closed cracks mainly affect the pressure diffusion of the slurry. A coupling effect exists between the dynamic water pressure and the grouting pressure. The final dynamic water pressure increases by $25 \%$ compared with the initial value under dynamic water pressure only. By contrast, the final dynamic water pressure increases by $31 \%$ compared with the initial value under the combined effect of dynamic water pressure and confining pressure. The grouting effect can be improved by increasing the grouting pressure, decreasing the dynamic water pressure, and extending the grouting time.
\end{abstract}

Keywords: Rock grouting, Model experiment, Dynamic water pressure, Confining pressure

\section{Introduction}

Grouting technology has been widely used in practical projects to reinforce tunnels [1], porous rock [2], and gravel foundation [3] for practicability and wide application range. However, rock grouting is a complex and covert system project. The effect of grouting is influenced by many factors, such as dynamic water pressure, confining pressure of surrounding rock, and type of slurry and grouting technology.

The mechanism of grouting can reinforce the surrounding rock is that the solidified slurry can block the water source and can increase the strength of the injected rock mass. That is, by influencing the microstructure, micropores can improve the macroscopic mechanical properties of rock. Finally, this technology can enhance the cohesion and internal friction angle of the structural surface [4].

Many previous studies on grouting theory have been conducted by scholars in China and abroad [5-7]. According to the different properties, grouting slurry has been divided into Newtonian fluid, Bingham fluid, and power law fluid. On the basis of these properties, different rheological constitutive equations have been obtained. Numerical simulation is an important method to research slurry motion.

*E-mail address: lqpzsq@163.com

ISSN: $1791-2377$ @ 2018 Eastern Macedonia and Thrace Institute of Technology. All rights reserved. doi:10.25103/iestr.113.16
It has advantages of low cost and fast speed but produces static results at a certain moment [8-11]. Thus, constantly measuring the changing parameters, such as grouting pressure and dynamic water pressure, is impossible in the entire grouting process. Field experiments have advantages of high accuracy. However, they are generally difficult to apply because of the high cost and harsh environment of the grouting construction site.

Indoor model experiments are visualized, real, and low cost. They can quantitatively or qualitatively analyze certain factors that affect the experimental results. From the analyses above, the indoor model experiments are found to have natural advantages for research on the grouting process. This model experiment used a "geological engineering multifunctional experimental system" to analyze the influence of dynamic water pressure and confining pressure on the grouting effect, which may provide certain references for grouting construction.

\section{State of the art}

The variability of the grouting construction environment leads to the complexity of the grouting effect. Research conclusions about the law of slurry flowing have been given by many scholars. However, most available results are based on the idealization of the slurry flowing model or the simplification of the grouting environment.

For example, Zhan, K.Y. developed a grouting model experimental system under flowing water conditions to study 
the influence of dynamic water pressure on the grouting effect $[12,13]$. The system has the advantages of stable and variable height of the water head. The rough cracks under flowing water conditions are conducive to the spread of slurry in the direction of the reverse and vertical flow. However, they are not conducive to the spread of slurry along the water flow. Gao, G. R. developed a method based on the actual dynamic water conditions in the mine [14]. The method can be used to simulate grouting under different dynamic water conditions. The system can achieve the flowing water conditions of the maximum flow rate of $78 \mathrm{~L} / \mathrm{min}$ and the maximum pressure of $7 \mathrm{MPa}$. Simultaneously, it can simulate the grouting materials of single and composite slurries. The maximum flow rate is $1 \mathrm{~L} / \mathrm{min}$, and the maximum pressure is $30 \mathrm{MPa}$. It lays a foundation for studying the influence of grouting materials on the grouting effect under different dynamic water conditions. However, only the factor of dynamic water pressure is considered in the studies above, and the possible influence of confining pressure is neglected.

Guo, M. W. developed a grouting experimental system under high-pressure environment to explore the influence of confining pressure on the grouting effect [15]. The change in pore water pressure can be obtained by means of sensor synchronous detection in the experimental system. The system can be used to study the seepage law of grouting slurry under high-pressure conditions. Kleinlugtenbelt $\mathrm{R}$ developed a $3 \mathrm{D}$ grouting system that can realize real-time monitoring of the pore water pressure and the total stress of the injected media. It can be used to study the sand body grouting mechanism [16]. Shen, G. L. studied the diffusion law of grouting slurry under different geological conditions in a $3 \mathrm{D}$ vacuum environment. He calculated the theoretical value of the slurry diffusion radius by using the selfdesigned indoor 3D vacuum grouting model [17].In all the studies above, only the influence of confining pressure on the grouting effect is considered, and the possible influence of dynamic water pressure is neglected.

Grouting experiments have been performed by researchers in complex environments. Yang, M. J. used a self-developed equipment to perform a single crack and a network crack grouting model experiment. The effect of different geometric cracks on rock grouting was studied, and the main differences between the non-Newtonian fluid seepage and the Newtonian fluid seepage in the grouting process were obtained. Their respective scopes of application were given in the end [18]. Zhang, W. J. developed an experimental system of 3D grouting model. The experimental system can realize porous grouting and multi-step grouting in different media, which have a realtime monitoring of the internal physical parameters of the rock mass. These features are important to the study of the permeability and reinforcement mechanism of the grouting slurry [19-21]. AC. Houlsby simulated the flowing of slurry through a single crack. The influence of slurry pressure, permeation rate, and other influencing factors on the different parts of the crack length direction was studied[22].All the studies above focus on the influence of the slurry flow channel on the grouting effect, and that of dynamic water pressure and confining pressure is neglected. The size effect also exerts some influences to the results of the experiments due to the limitation of the size of experimental devices.

In addition to experimental works, theoretical analysis and finite element numerical simulation are commonly used methods. Their results have also been accepted by practical engineering and scientific research. For example, Li, S. C. regarded slurry as Bingham fluid. A flood-diffusion model was proposed under the assumption of a generalized Bingham model and a single plate. The diffusion distance equation was obtained in the end by considering the flow variable characteristics of slurry [23]. Jian, W. B. calculated the dynamic elastic modulus by elasticity theory. Different deformation parameters were obtained before and after grouting. The grouting effect was experimented using acoustic wave technology for the different directions of rock mass with different weathering degrees [24]. Yang treated grouting fluid as Bingham fluid, and the flowing of the slurry in single and multiple cracks were simulated. The correctness of the model was verified by experiments [25]. However, the disadvantage of theoretical analyses is that they assume and abstract the properties of slurry to simplify the calculation process. For example, Li, S. C. and Yang regarded grouting slurry as Bingham fluid. The various complex changes in the slurry in the grouting process were limited artificially.

The discussion above indicates that many studies on grouting have been done by many scholars. None has considered grouting under the combined effect of dynamic water pressure and confining pressure. And experimental system under dynamic water pressure and confining pressure has not yet been designed. On the basis of these considerations, this study uses a "geological engineering multifunctional experimental system". The system is used to simulate the diffusion law of grouting slurry and the karst aquifer reinforcement effect under dynamic water pressure and confining pressure. By observing the main indicators of slurry diffusion and slurry consolidation retention, the grouting effect is explored, and the ideal experimental results are obtained [26-31].

The remainder of this study is organized as follows. Section 3 describes experimental methodology in this study. Section 4 gave the grouting results of cracks and aquifer, then gave the on-site observation results. Conclusions are summarized in Section 5.

\section{Methodology}

\subsection{Experiment equipment}

A self-developed "geological engineering multifunctional experimental system" is used in this experiment (Fig.1).

The experimental system consists of a mainframe loading frame, an axial servo system, a lateral servo system, a water injection servo system, a multi-channel electrohydraulic servo control system, an automatic hydraulic pump station, and a data processing unit. The hydraulic system is adopted to achieve axial pressure and bidirectional control of pressure and displacement. A loaded bladder system is adopted for the horizontal pressure. Mutual restraint between two pairs of pressure is avoided given that the loaded bladder is a flexible body. The pressure and displacement control in the stress loading process can be completed by the control system. The purpose of pressure loading and data acquisition can be achieved by the entire process control of the hydraulic loading. The main feature of the "geological engineering multifunctional experimental system" is that it can achieve a true triaxial compression test. Given its large pressure chamber, the size effect of the general 3D loading equipment can be avoided. Grouting under the combined effect of dynamic water pressure and confining pressure can also be achieved by the system. 


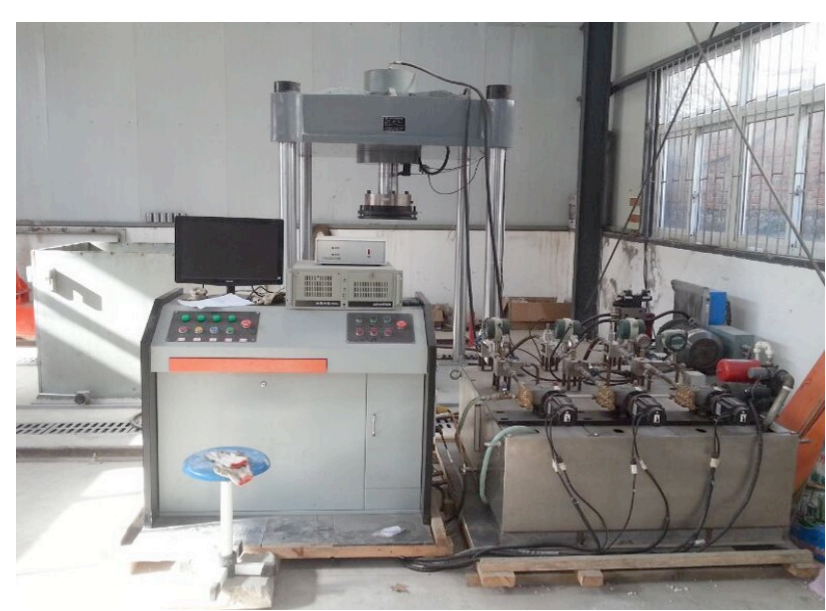

(a)

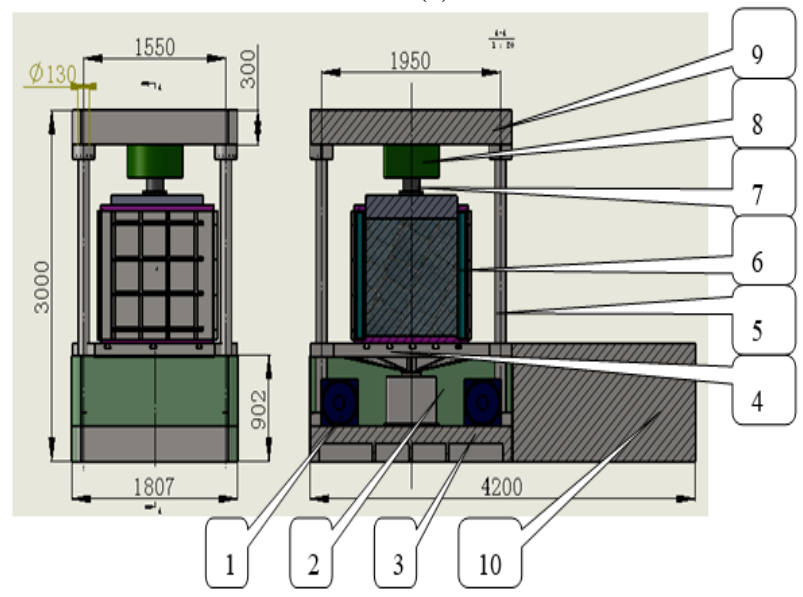

(b)

1- bearing plate; 2- axial servo cylinder; 3- break pressure tank; 4loaded plate; 5- stand column;6-pressure chamber; 7- connector; 8- load sensor; 9- bearing plate; 10 - operating platform

Fig. 1. Geological engineering multifunctional experimental system. (a) Real product of experimental system. (b) Schematic of experimental system

\subsection{Experiment scheme}

The size of the experimental model should match the size of the experimental system pressure chamber. Length, width, and height are 1500,1000 , and $1000 \mathrm{~mm}$, respectively. Fig.2 shows the experimental scheme.
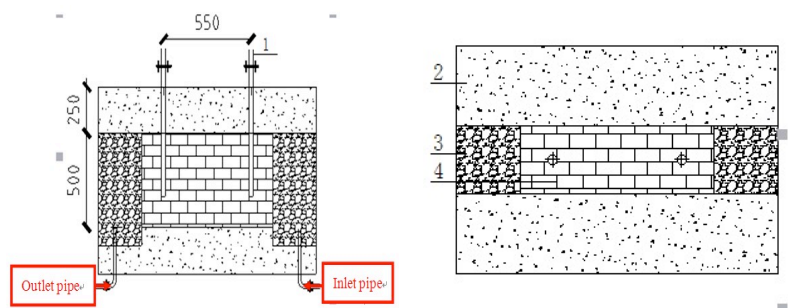

1-grouting pipe; 2-aquifer; 3-boundary material aquifers; 4-rock mass

Fig. 2. Schematic of experimental scheme

(1) Four groups of comparative experiments were designed according to the purposes of the experiment and the characteristics of the experimental system:

Group1: grouting under no dynamic water pressure or confining pressure;

Group2: grouting under dynamic water pressure only;

Group3: grouting under confining pressure only;

Group4: grouting under dynamic water pressure and confining pressure.
The same grouting model was adopted for the four groups of experiments. The grouting model was built by the same boundary material, crack size, grouting time, and grouting pressure.

(2)P.O 32.5 cement was selected as the grouting material. White cement with a water-cement ratio of 0.75 was used in this experiment to facilitate the observation of the experimental process. The grouting rock mass was made of gypsum, ash calcium, sand, and a small amount of tap water. Gypsum, ash calcium, and sand were prepared at 1.46:0.36:11.76 (by weight). The corresponding blocks were made using the same materials. Boundary materials were also made from the proportioning materials above. The aquifer was filled with architectural ceramsite and gravel to ensure the water permeability of the aquifer (Fig.3). The cracks in the rock mass were simulated with reserved gaps in the gypsum masonry. The width of crack was approximately $1.5 \mathrm{~mm}$, and the length was $450 \mathrm{~mm}$. They were controlled by means of adhesive tape holders.

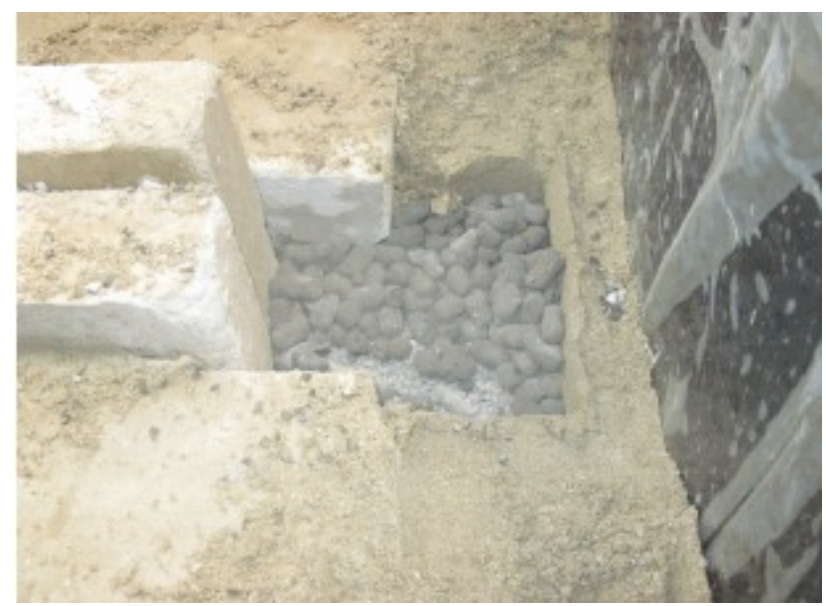

Fig. 3. Simulation of aquifer

(3) The experimental model must be continuously cast to ensure no cracks between the grouting rock mass and the boundary material. The boundary material was poured in layers, and the interval between each layer was 40 minutes to ensure the initial congeal of the pouring material.

(4)Two-layer plastic film was laid on the top, bottom, and boundary of the model to ensure the waterproofness and leakproofness of the model boundary and aquifer (Fig.4).

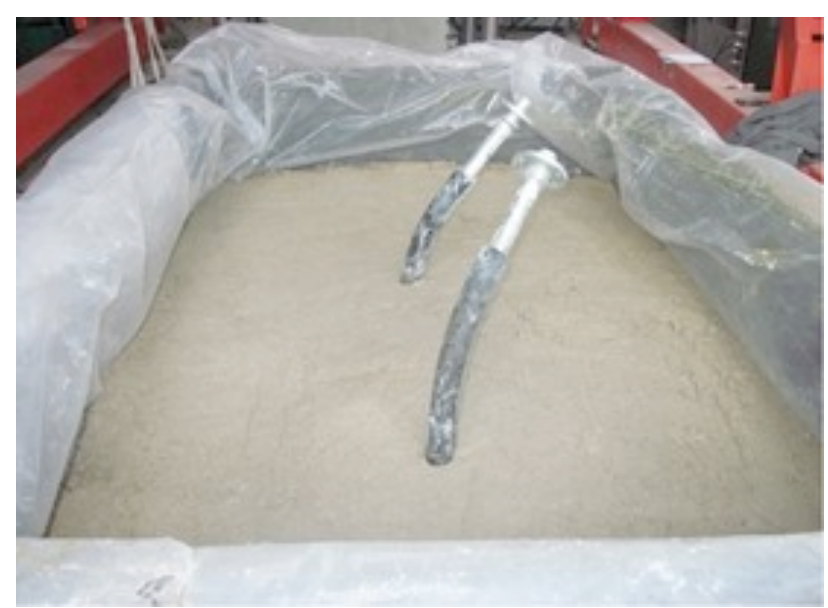

Fig.4. Molding process diagram 


\subsection{Experiment procedure}

Except for the model experiment of group1, those of the three other groups must be completed with the "geological engineering multifunctional experimental system" following the experimental scheme. The specific experimental steps are described in detail by group 4 "grouting under dynamic water pressure and confining pressure".

(1) Molding: First, the pressure chamber of the experimental system should be cleaned and fully dried. The lateral pressure capsule of the pressure chamber was installed. A protective layer outside the pressure capsule was installed to prevent the pressure capsule from being damaged. The molder was lifted into the pressure chamber. The inlet and outlet pipes were sealed in the pressure chamber with a geotextile to prevent the experimental material from flowing out. The inner part of the molder was lubricated, and a waterproof PVC film was laid to facilitate the removal of mold. Finally, the model was cured for 24 hours in accordance with the experimental program.

(2) Connection: Tap water was injected into the lateral loading capsule until the water in the capsule was about to overflow. The molder was slowly lifted from the pressure chamber, and the model was wrapped with waterproof film to ensure its tightness. The inlet and outlet pipes were connected to the water line, and the lateral loading capsule was connected to the lateral loading servo system. The upper cover of the pressure chamber was installed, and the pressure chamber was pushed below the vertical actuator of the main machine of the experimental system.

(3) Loading: The operating system should be turned on and set with the upper limit of loading. The vertical pressures $\mathrm{P} 1, \mathrm{P} 2$ (the pressure parallel to the crack direction), and $\mathrm{P} 3$ were $0.2 \mathrm{MPa}, 0.2 \mathrm{MPa}$, and $0.15 \mathrm{MPa}$, respectively. The vertical and lateral loading systems were turned on, and the model rock mass was loaded slowly and uniformly. The water pump was turned on to fill the pressure chamber. The servo system was started to ensure that the dynamic water pressure was maintained at approximately0.16MPa (Fig.5).

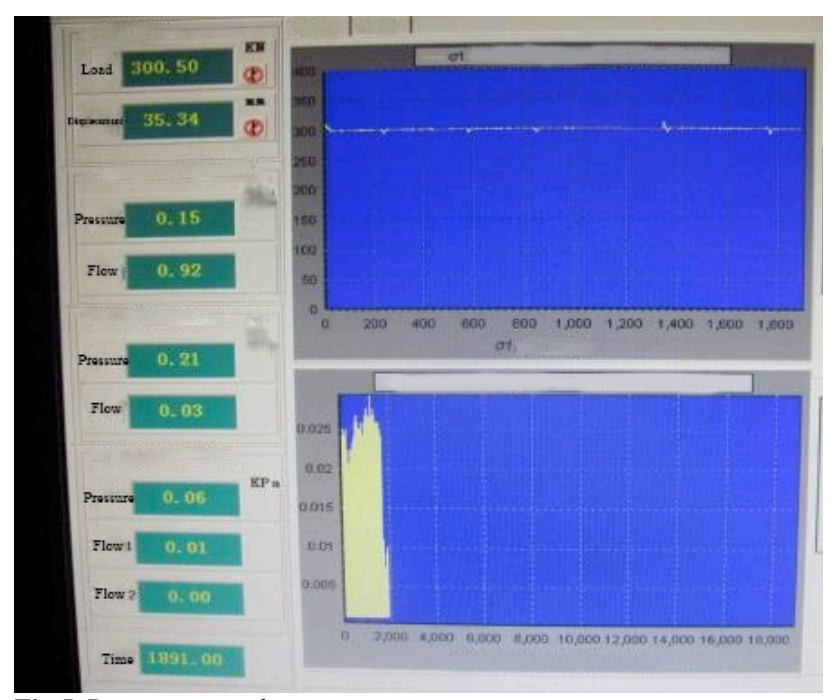

Fig.5. Pressure control system

(4)Grouting: The grouting pump should be cleaned prior to grouting. The cement slurry should be mixed in the watercement ratio of 0.75 and should be evenly mixed in the slurry barrel. The grouting pressure of the grouting pump should be adjusted to $0.75 \mathrm{MPa}$. When the loading pressure reached the set value, the value was kept for 8 hours. After the process had been completed, grouting was started. The pump pipe was connected with the grouting pipe jointed in the grouting rock model. Grouting was kept for 45 seconds. After grouting, the pump was turned off. During the grouting process, the changes in dynamic water pressure were monitored and recorded by the servo system.

(5) Demolishing the model: The pressure was held for 12 hours, and the model was removed. The dynamic water pressure and confining pressure should be closed prior to turning off the experimental system. The inlet and outlet pipes were disconnected. The lateral loading capsule and the pressure chamber upper cover were removed. The pressure chamber was pushed out of the main machine, and the top plate was dug to observe the grouting effect.

\section{Result Analysis and Discussion}

After demolishing the model, the model is found relatively intact, and the cement slurry does not overflow. Therefore, the grouting model does not show splitting under the grouting pressure. Thus, the grouting pressure meets the experimental requirements [32-34].

\subsection{Crack grouting effect}

The following figures show the effect of crack grouting experiment in each group.

The crack grouting effect under no dynamic water pressure or confining pressure is the best. The entire model crack is filled with white cement slurry and is compacted. The crack near the grouting tube is expanded to $4 \mathrm{~mm}$ given the influence of grouting pressure (Fig.6).

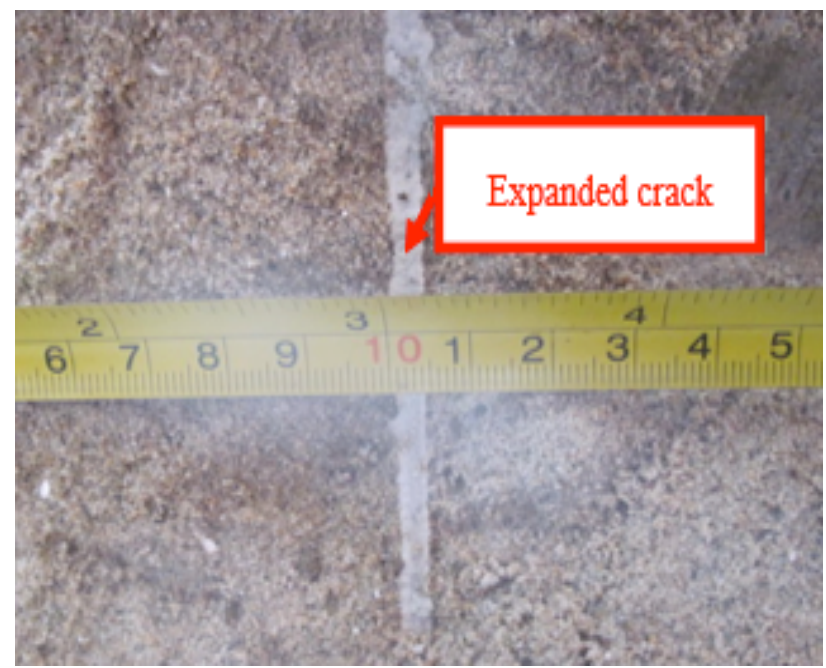

Fig. 6. Grouting effect of cracks under no dynamic water pressure or confining pressure

The grouting effect of the crack is relatively poor under dynamic water pressure. The overall expansion of the model cracks is obvious with a width of $3-3.5 \mathrm{~mm}$ for the combined impact of dynamic water pressure and grouting pressure. Many gaps are still found although traces of white cement grouting fill in the cracks. The reason is that, although the slurry spreads to this location, the dynamic water pressure washes it away. Thus, the slurry is not consolidated and retained (Fig.7).

The grouting effect under confining pressure only shows that the crack is basically filled. However, the model crack closes due to the confining pressure. The width of crack after slurry filling is only approximately $1 \mathrm{~mm}$. The spread of the slurry is also impeded (Fig. 8). 


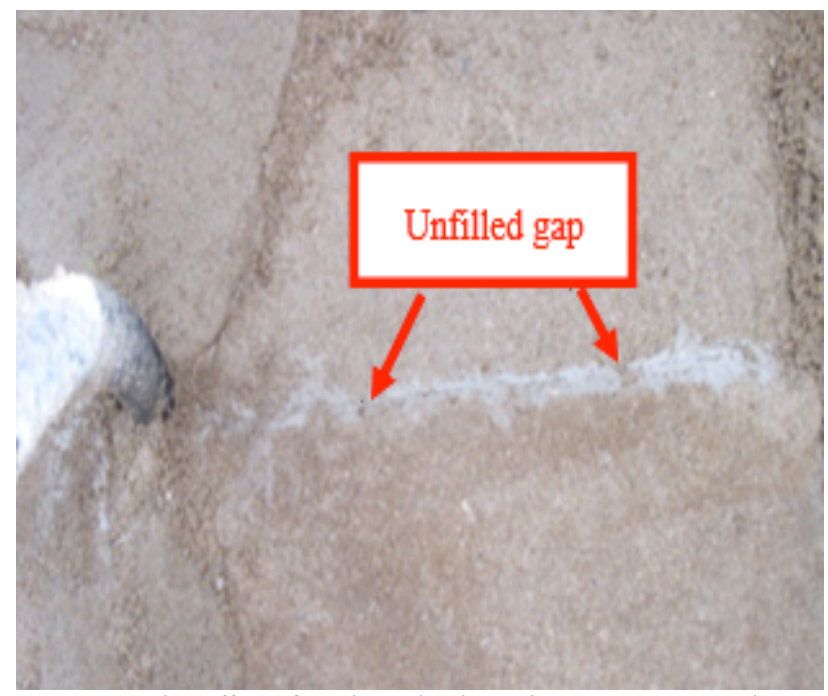

Fig. 7. Grouting effect of cracks under dynamic water pressure only

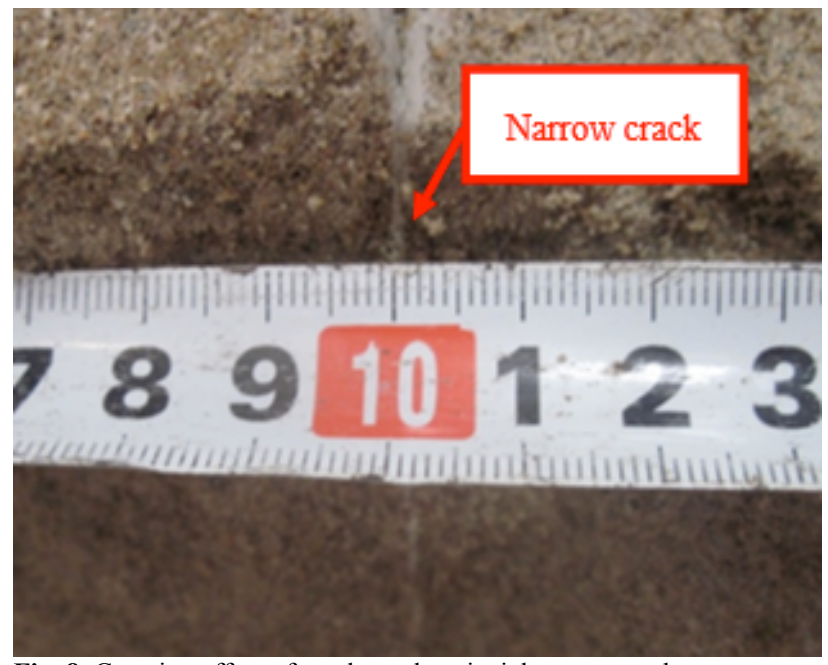

Fig. 8. Grouting effect of cracks under triaxial pressure only

The grouting effect under dynamic water pressure and confining pressure is the worst. The model cracks close, and the crack filling rate is low. Thus, the slurry diffusion and consolidation retention are greatly affected. The grouting effect of each group shows that the filling effect of cracks on the adjacent side of the grouting pipe is remarkably better than that of the far side. Therefore, the grouting pressure decreases with the extension of the grouting distance.

\subsection{Aquifer grouting effect}

Figs. 9 to 12 show the grouting effect of the experimental aquifer in each model group.

In group 1 , the aquifer is completely filled with the slurry. The white cement slurry spreads to the aquifer and cement together with gypsum masonry (Fig.9).

In group 2, the cement slurry is removed and transported by dynamic water pressure after filling although the aquifer is basically filled with cement slurry. The gypsum masonry is poorly consolidated with the white cement slurry and has a loose structure (Fig.10). The filling structure of the aquifer near the outlet pipe is slightly dense compared with that near the inlet pipe because the slurry is brought to the outlet pipe by dynamic water pressure and consolidated with the aquifer. The dynamic water pressure mainly affects the consolidation of the slurry.

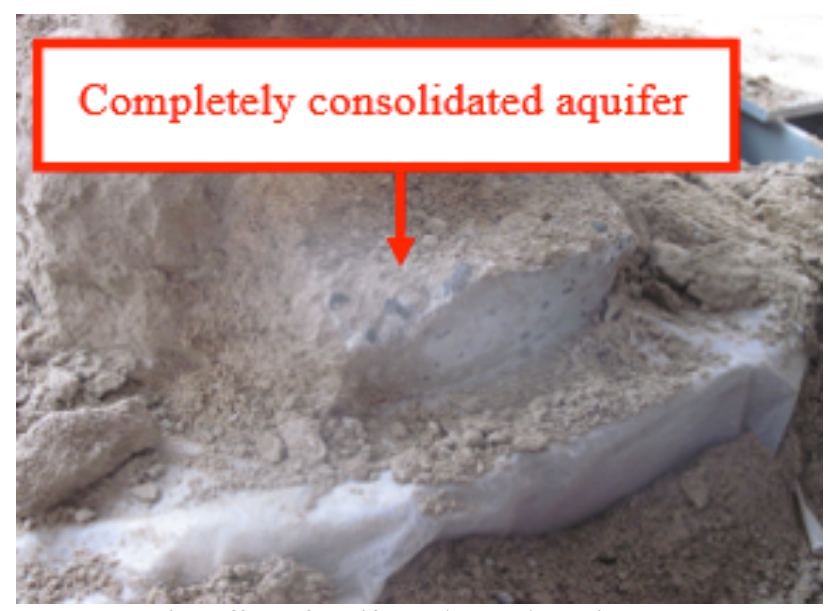

Fig. 9. Grouting effect of aquifer under no dynamic water pressure or confining pressure

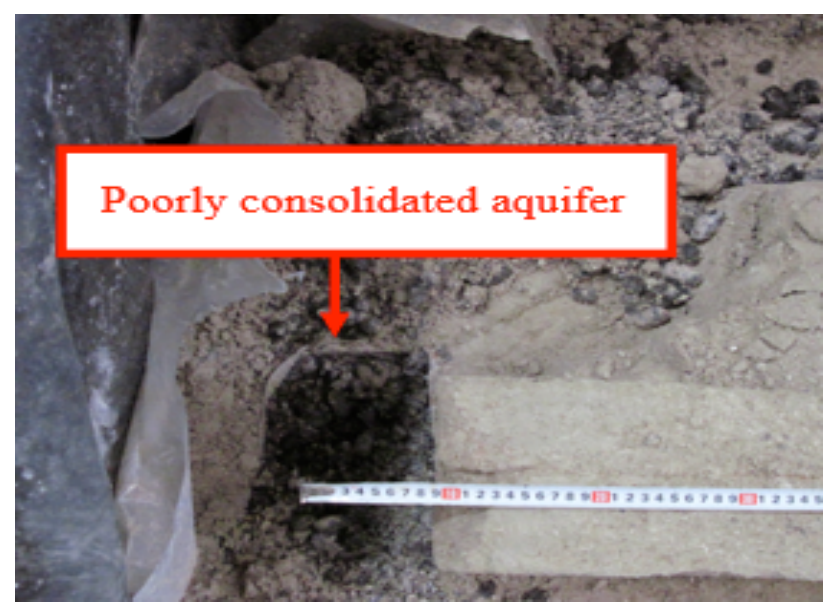

Fig. 10. Grouting effect of aquifer under dynamic water pressure only

In group 3, the effect of aquifer grouting near the grouting pipe is better than that away from the grouting pipe. Therefore, the grouting pressure decreases with the extension of the grouting distance, which results in less cement slurry flowing into the aquifer. The main influence under confining pressure is the spread of the slurry. The confining pressure is favorable to the consolidation of the slurry given that the white cement slurry shows regionally concentrated cementation (Fig.11).

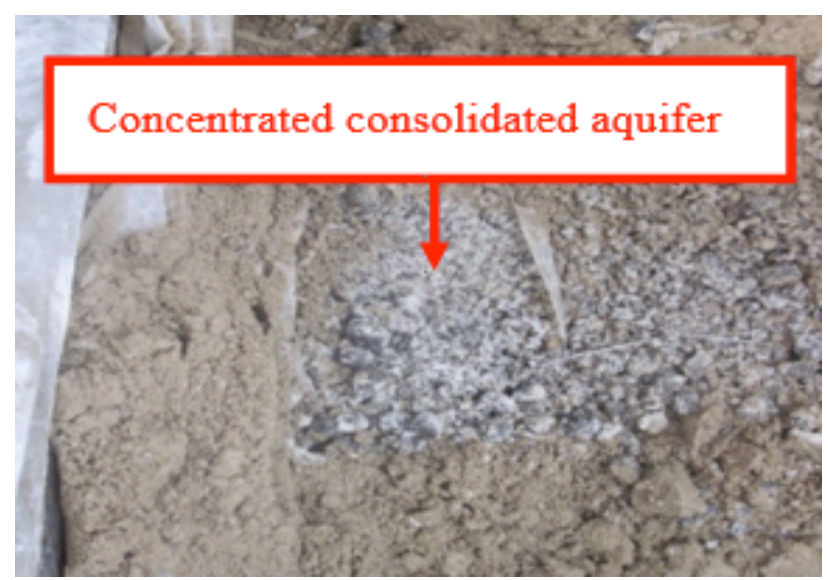

Fig. 11. Grouting effect of aquifer under confining pressure only

The effect of aquifer grouting under dynamic water pressure and confining pressure is poor compared with that in the three other groups above. Nearly no white cement slurry flows into the aquifer. Many unfilled voids are left, 
and the filling structure is loose. This condition indicates that the grouting slurry diffusion and consolidation retention are affected, which greatly reduces the grouting effect (Fig.12).

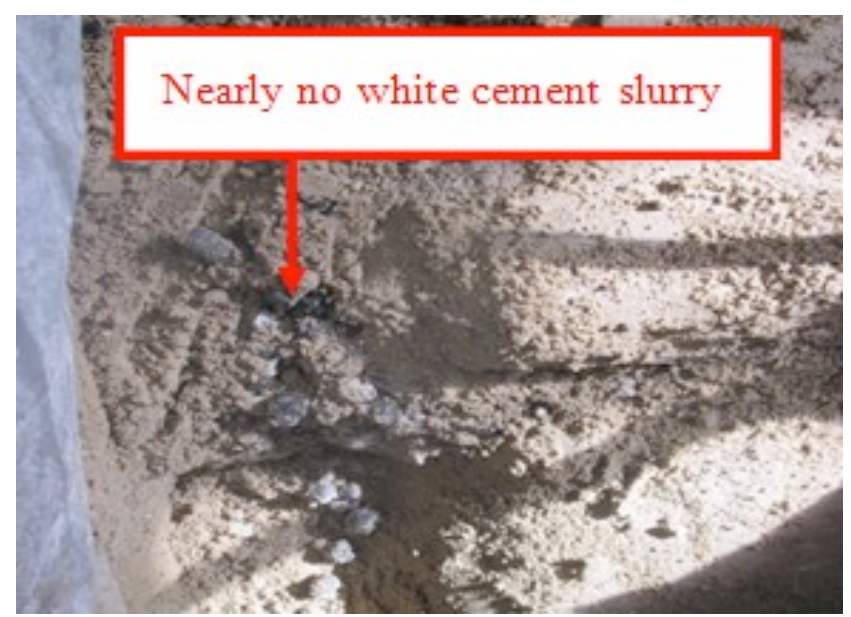

Fig. 12. Grouting effect of aquifer under dynamic water pressure and confining pressure

\subsection{The change law of dynamic water pressure}

Fig.13 shows the change curve of dynamic water pressure with grouting time under dynamic water pressure only. It shows that the dynamic water pressure is close to $0.16 \mathrm{MPa}$ at the beginning of grouting. When grouting time reaches 25 seconds, the dynamic water pressure increases rapidly until it reaches a peak of $0.2 \mathrm{MPa}$ at the end of grouting. The grouting pressure also increases slightly. In the end, the dynamic water pressure increases by $25 \%$ from the initial value. Therefore, the dynamic water pressure and the grouting pressure show a mutual coupling effect in the grouting process.

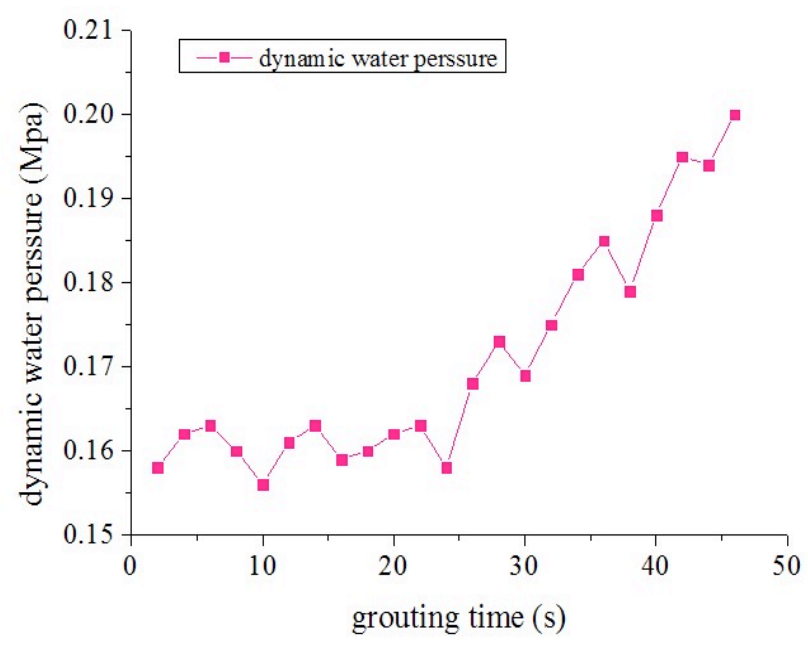

Fig. 13. Under dynamic water pressure only

When grouting under dynamic water pressure and confining pressure, the initial dynamic water pressure is slightly higher than $0.16 \mathrm{MPa}$. The pressure begins to increase rapidly at 25 seconds and reaches a peak of 0.21 $\mathrm{MPa}$ at the end of grouting, which increases by $31 \%$ from the initial value (Fig.14).

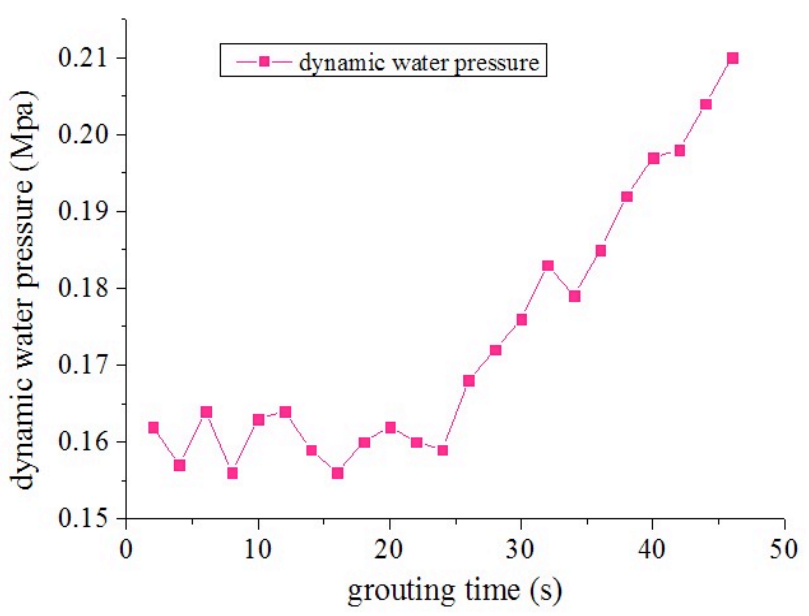

Fig. 14. Under dynamic water pressure and confining pressure

The grouting pressure increases to $1 \mathrm{MPa}$ in the end. The final grouting pressure is greater than the sum of the initial dynamic water pressure and the initial grouting pressure (Fig. 15).

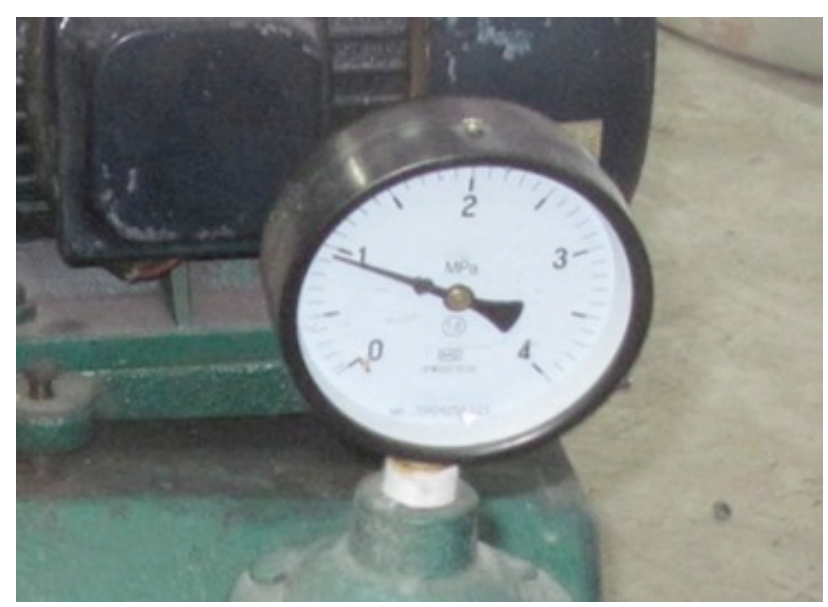

Fig. 15. Final grouting pressure under dynamic water pressure and confining pressure

\subsection{Analysis of experiment results}

The results of four groups of experiments show that the grouting effect mainly depends on whether the slurry can be smoothly spread and whether the slurry can be successfully consolidated and retained. The reason why the dynamic water pressure and confining pressure affect the grouting effect can be summarized as follows:

(1)From the results of groups 1 and 2, the flowing water is concluded to dilute the slurry, which leads to its viscosity to decrease. As a result, the slurry easily flows with water out of the model cracks. The grouting pressure causes the increase in dynamic water pressure, which results in a considerable expansion of the cracks in the model structure surface. The grouting space is increased, and the slurry is highly difficult to consolidate and retain. Therefore, dynamic water pressure mainly influences the grouting effect by affecting the consolidation of the slurry.

(2)From the results of groups 1 and 3, the grouting filling and cementing effect of aquifer under confining pressure is found to be weak given that the normal stress of the cracks in the structural surface increases and that the cracks close. Accordingly, the slurry injection in the cracks decreases. Thus, the slurry that flows through the cracks into the aquifer is reduced. Therefore, the confining pressure 
mainly influences the grouting effect by affecting the spread of the slurry.

(3)From the results of groups 1 and 4 , the combined influence of the dynamic water pressure and the confining pressure is found to considerably negatively influence the effect of cracks grouting and aquifer reinforcement. The confining pressure (normal force on the crack surface) enables closing of the crack surface of the rock mass. When the dynamic water pressure is coupled with the grouting pressure, the original dynamic water pressure is increased. These factors adversely affect the consolidation of the slurry.
Therefore, other grouting parameters must be changed to achieve the intended purpose of grouting, such as increasing the grouting pressure, extending the grouting time, and even reducing the dynamic water pressure.

\subsection{On-site observation results}

From the on-site observations, the karst aquifer can be divided into the following four categories according to a single-hole maximum hydraulic discharge and grouting amount for unit volume. Table 1 shows the results of the division.

Table 1. Karst structure type and its classification index

\begin{tabular}{|c|c|c|c|c|}
\hline Type & $\begin{array}{l}\text { Single hole maximum hydraulic } \\
\text { discharge } \\
\mathrm{m}^{3} / \mathrm{h}\end{array}$ & $\begin{array}{l}\text { Grouting amount for unit } \\
\text { volume } \\
L / \mathrm{m}^{3}\end{array}$ & $\begin{array}{l}\text { Karst aquifer Spatial structure } \\
\text { type }\end{array}$ & $\begin{array}{ll}\text { Karst } & \text { fissure } \\
\text { development } & \end{array}$ \\
\hline I & $>80$ & $>100$ & $\begin{array}{l}\text { Dissolved-hole } \\
\text { network structure }\end{array}$ & Extremely serious \\
\hline II & $40 \sim 80$ & $30 \sim 100$ & $\begin{array}{l}\text { Dissolved-pore } \\
\text { network structure }\end{array}$ & serious \\
\hline III & $10 \sim 40$ & $5 \sim 30$ & $\begin{array}{l}\text { Dissolved-gap } \\
\text { network structure }\end{array}$ & Moderate \\
\hline IV & $<10$ & $<5$ & $\begin{array}{l}\text { Single-fractured } \\
\text { structure }\end{array}$ & poor \\
\hline
\end{tabular}

As shown in Table 1, the single-fractured network structure limestone aquifer in the coal mine is an area with poor karst development. The influence of dynamic water pressure is relatively small. The grouting is considered to occur under high-pressure environment. The curve of grouting pressure with time is steep. The orifice pressure (equivalent to the grouting pressure in the experiment) rises rapidly with time. During grouting, the orifice pressure reaches the final grouting pressure in a short time. Thus, the slurry consumption is small, and the grouting difficulty is relatively small. Figs. 16 and 17 show that the grouting time for the Z2-2 orifice in the 2667 working face of the Liuyi Mine is approximately 5 hours, and the grouting time for the JZ3-4 orifice in the 26117 working face of the Hengyuan Mine is approximately 12 hours.

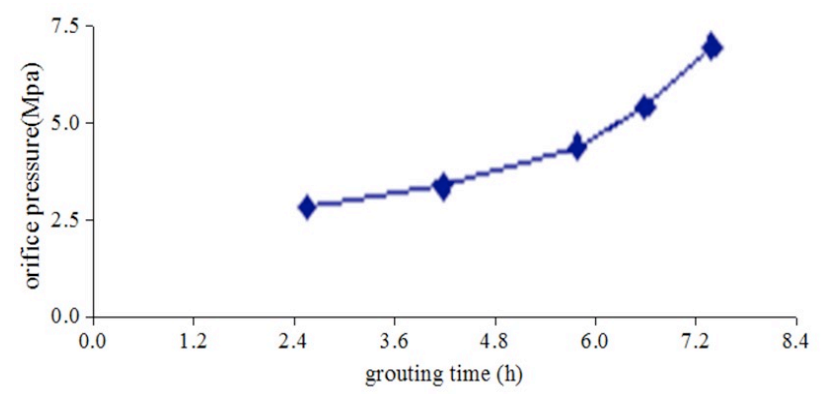

Fig. 16. Grouting time for the Z2-2 orifice in the 2667 working face of the Liuyi Mine

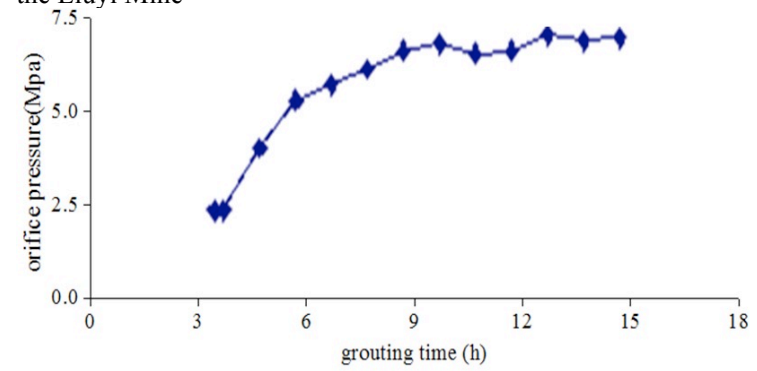

Fig. 17. Grouting time for the JZ3-4 orifice in the 26117 working face of the Hengyuan Mine
By contrast, the limestone aquifer with the dissolvedhole network structure belongs to the region where karst development is extremely serious. The environment is of a typical high dynamic water pressure and high confining pressure. The data observed at this site show that the curve of the grouting pressure with time changes slowly. The orifice pressure rises slowly with time, and the orifice pressure takes a long time to reach the final grouting pressure. The consumption of grouting slurry is greatly increased, and the construction becomes more difficult than before. Figs. 18 and 19 show that the grouting time for the Z5-4 orifice in the 663 working face of the Liuyi Mine is approximately 240 hours, and the grouting time for the J7-4 orifice in the 1023 working face of the Wugou Mine is approximately 110 hours.

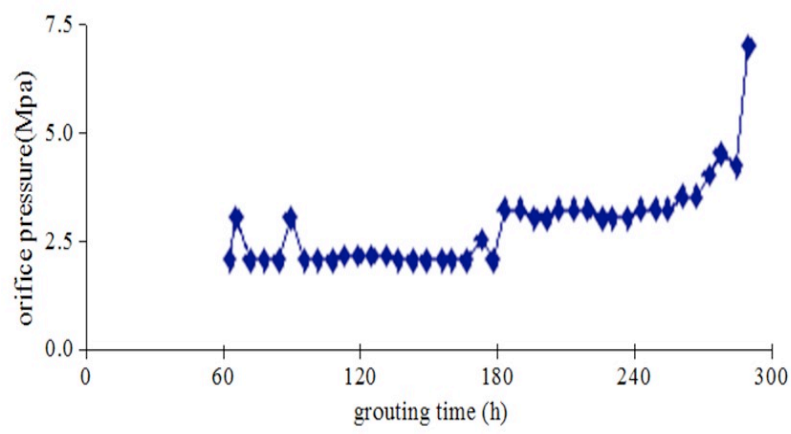

Fig. 18. Grouting time for the Z5-4 orifice in the 663 working face of the Liuyi Mine

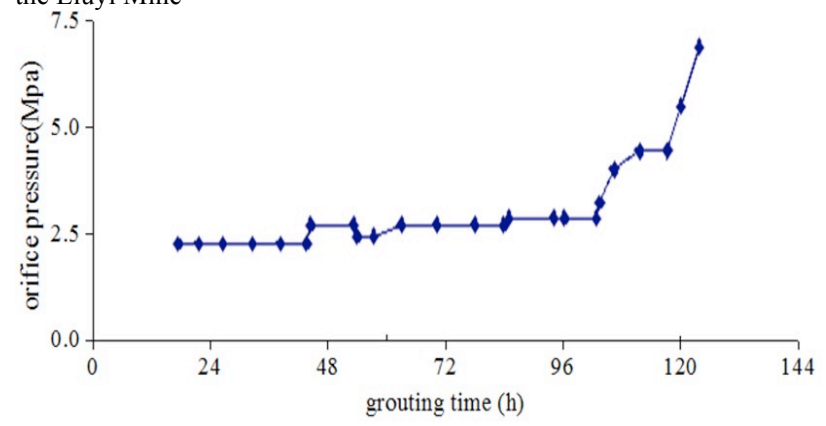

Fig. 19. Grouting time for the J7-4 orifice in the 1023 working face of the Wugou Mine 
The reliability of the model experimental results is further validated by the results of on-site observations. The "geological engineering multifunctional experimental system" can simulate grouting under dynamic water pressure and confining pressure. On-site observation data show that the grouting time in high confining pressure and high dynamic water pressure environment is much longer than that in high confining pressure only. At the same final grouting pressure (approximately7.5MP), the longer the grouting time is, the more slurry is required, and the more difficult the grouting is. Thus, grouting construction should avoid the simultaneous existence of high dynamic water pressure and high confining pressure.

\section{Conclusions}

To simultaneously consider the influence of dynamic water pressure and confining pressure on the grouting effect, four contrast groups of grouting experiments for cracked rock were completed using a "geological engineering multifunctional experimental system". Individual influencing factors were analyzed separately, and conclusions were obtained as follows:

(1) The effect of grouting is mainly affected by two factors: whether the slurry can be spread smoothly, and whether the slurry can be consolidated and retained.

(2) The spread of the slurry is mainly affected by the confining pressure. The diffusion radius of grouting slurry is proportional to the grouting pressure. Thus, the grouting effect can be improved by increasing grouting pressure in an environment with high confining pressure.

(3) The consolidation of the slurry is mainly affected by the dynamic water pressure. When grouting is in the confined water zone, measures should be taken to reduce the dynamic water pressure or use chemical slurry that can be cemented quickly.
(4) The slurry diffusion and the consolidation retention are affected when dynamic water pressure and confining pressure coexist due to a coupling effect that exists between the dynamic water pressure and the grouting pressure. The dynamic water pressure increases by $31 \%$, and the final grouting pressure is greater than the sum of the initial grouting pressure and dynamic water pressure in this experiment. Thus, the spread and consolidation of the slurry are greatly affected.

The factors influencing grouting effect were systematically studied using the "geological engineering multifunctional experimental system". Notably, the grouting effect needs to be further studied under the combined influence of dynamic water pressure and confining pressure. The confining pressure decreases the width of the cracks in the rock mass. The smaller the crack width, the greater the grouting resistance is. However, the fluidity of the slurry deteriorates due to the compression of the cracks in the rock at the same time. The degree of dilution by water in the water-conducting channel is correspondingly reduced, which facilitates the rapid cementation of the slurry. In case of grouting in a flowing water environment, the dilution of the slurry by the dynamic water pressure will be greatly reduced if the slurry cements quickly. From this perspective, the confining pressure is beneficial to the grouting effect. The confining pressure and dynamic water pressure exert a coupling influence on the grouting effect. A fitting point with the best grouting effect under dynamic water pressure and confining pressure is found and has a better influence on the grouting construction in the complex environment. This topic requires detailed and comprehensive research.

\section{Acknowledgments}

This work was supported by the Major Universities Natural Science Research Project in Anhui Province (KJ2016SD19).

This is an Open Access article distributed under the terms of the Creative Commons Attribution License

\section{References}

1. Fransson, C.-F. Tsang, J. Rutqvist, G. Gustafson, "Estimation of deformation and stiffness of fractures close to tunnels using data from single-hole hydraulic experimenting and grouting”. International Journal of Rock Mechanics and Mining Science, 6(47), 2010, pp.887-893.

2. Jiang C. L., Jiang Z.Q., Liu S.D., Sun Q., Yang C., "Chemical grout diffusion in porous rock based on response of geoelectric field". International Journal of Mining Science and Technology, 23(5), 2013, pp.643-646.

3. Cheng, P.D., Li, L., Tang, J., et al, "Application of time-varying viscous grout in gravel-foundation anti-seepage treatment". Journal of Hydrodynamics, 23(3), 2011, pp.391-397.

4. Rikard Gothäll, Håkan Stille, "Fracture-fracture interaction during grouting". Tunneling and Underground Space Technology, 25(3), 2010, pp.199-204.

5. D.Gouvenot, "State of the art in European grouting". Proceedings of the Institution of Civil Engineers-Ground Improvement, 2(2), 2015, pp.51-67.

6. Gustafson G, Claesson J, Fransson Å, "Steering parameters for rock grouting". Journal of Applied Mathematics, 2013, pp.1-9.

7. Bezuijen A, Grotenhuis R TE, Van TOL A F, et al, "Analytical model for fracture grouting in sand". Journal of Geotechnical and Geoenvironmental Engineering, 137(6), 2010, pp.611-620.

8. S.A. Sadrnejad, "Numerical solution and hydrodynamics of grout propagation in porous media". Iranian Journal of Science and Technology Transaction B-Engineering, 30(B1), 2006, pp.151-155.
9. Kate Saunders, Mahesh Prakash, Paul W, Cleary, Mark Cordell, "Application of smoothed particle hydrodynamics for modelling gated spillway flows”. Applied Mathematical Modelling, 38(17), 2014, pp.4308-4322.

10. Yu J. H., Greg T. "Reconstructing surfaces of particle based fluids using anisotropic kernels". ACM Transactions on Graphics, 32(1), 2013, pp. 1-12.

11. Liu, X. J., Zhong, D. H., Tong, D. W., et al, "Dynamic visualization of storm surge flood routing based on three-dimensional numerical simulation". Journal of Flood Risk Management, 9(2), 2016, pp. 136-153.

12. Zhan, K. Y., Sui, W. H., "Design of Model experiment System for Grouting into a Single Fracture with Flowing Water". Research and Exploration in Laboratory, 30(10), 2011, pp.19-23 (in Chinese).

13. Zhan, K. Y., "Comparative Experimental Investigation of Grouting with Flowing Water into a Smooth or Rough Fracture". Chinese Journal of Underground Space and Engineering, 10(3), 2014, pp.599-603(in Chinese).

14. Gao, G. R., An, X. L., Chen, H., Pu, C. Y., "Development and Application of Indoor Dynamic Water Grouting Simulation experiment Bench". Mine Construction Technology, 32(1/2), 2011, pp.32-34 (in Chinese).

15. Guo, M. W., Sui, W. H., "Design of Model Experiment System for Grouting under High Pressure Conditions". Journal of Engineering Geology, 18(5), 2010, pp.720-724 (in Chinese).

16. R Kleinlugtenbelt, "Compensation grouting, laboratory experiments in sand". Master thesis of Delft University of Technology, 2005, pp.85-90. 
17. Shen, G. L., "Research on Simulation experiment of Vacuum Grouting under Different Stratum". Master thesis of China University of Geosciences, China, 2016, pp.41-52.

18. Yang, M. J., Chen, M. X., He, Y. N., "Grouting simulation experiments on fractured rock mass". Journal of Experimental Mechanics, 16(1), 2001, pp.105-112 (in Chinese)

19. Zhang, W. J., Li, S. C., Wei, J. C., Zhang, Q. S., Zhang, X., Li, Z. P., Xie, D. L., "Development of a 3D grouting model experiment system and its application”. Rock and Soil Mechanics, 37(3), 2016, pp.902-911(in Chinese).

20. Li, L. P., Li, S. C., Zhao, Y., Wang, H. P., Liu, Q., Zhao, Y., Yuan, X. S., "3D Geomechanical Model for Progressive Failure Progress of Weak Broken Surrounding Rock in Super Large Section Tunnel". Chinese Journal of Rock Mechanics and Engineering, 31(3), 2012, pp.550-560 (in Chinese).

21. Cheng, P., Zou, J. F., Li, L., et al, "Experiment of fracture grouting in alluvium with physical model". Journal of China University of Geosciences, 38(3), 2013, pp. 649-654 (in Chinese).

22. AC. Houlsby, "Construction and design of cement grouting". New York: A Wiley-Interscience Publication, America, 1990, pp.1-10.

23. Li, S. C., Zhang, W. J., Zhang, Q. S., Zhang, X., Liu, R. T, Pan, G. M., Li, Z. P., Che, Z. Y., "Research on advantage-fracture grouting mechanism and controlled grouting method in water-rich fault zone". Rock and Soil Mechanics, 35(3), 2014, pp.744-752.

24. Jian, W. B., Zhang, D., Xu, X. T., "Analysis of consolidation grouting effect of fractured rock mass based on wave velocity experiment". Rock and Soil Mechanics, 35(7), 2014, pp.1943-1949.

25. Yang, M. J., Yue, Z. Q., Lee P. K. K., et al, "Prediction of grout penetration in fractured rocks by numerical simulation". Canadian Geotechnical Journal, 39 (6), 2002, pp.1384-1394.

26. Zhang, X., "Study on mechanism of slurry diffusion and sealing at the process of underground engineering moving water grouting and its application". Doctoral Dissertation of Shan Dong University, China, 2011, pp.49-54.
27. Happel J, Brenner H, “Low Reynolds number hydrodynamics: with special applications to particulate media". Berlin: Springer Science and Business Media, Germany, 2012, pp.159-234.

28. Barth T, Reiche M, Banowski M, et al, "Experimental investigation of multilayer particle deposition and resuspension between periodic steps in turbulent flows". Journal of Aerosol Science, 64(1), 2013, pp.111-124.

29. Kemp B A, Whitney J G, "Nonlinear nature of micro-particle detachment by an applied static field". Applied Physics Letters, 102(14), 2013, pp. 1- 4.

30. BÉG TA, Rashidi MM, BÉG O A, et al, "Differential transform semi-numerical analysis of biofluid-particle suspension flow and heat transfer in non-Darcian porous media". Computer Methods in Biomechanics and Biomedical Engineering, 16(8), 2013, pp.896907.

31. Haji H, Saouab A, Park C H, "Particles deposit formation and filtering: numerical simulation in the suspension flow through a dual scale fibrous media". Macromolecular Symposia, 340(1), 2014, pp. 44-51.

32. Hang, Y., Zhang, G. L., Yang, G. Y., "Numerical simulation of dewatering thick unconsolidated aquifers for safety of underground coal mining". Mining Science and Technology, 19(3), 2009, pp. 312-316.

33. Sui, W. H., Liu, J. Y., Yang, S. G., et al, "Hydrogeological analysis and salvage of a deep coalmine after an underground water inrush". Environmental Earth Sciences, 62(4), 2011, pp. 735-749.

34. Wang, D. L., Jiang, Z. Q., "Characteristics of water inflow and chemical grouting treatment of a Liu Yuanzi coal mine shaft in the Ordos Basin”. Mining Science and Technology, 20(4), 2010, pp. 607-610. 